\title{
Reinforcing a Turnaround Strategy for Municipalities to Improve Performance
}

Malefetsane Mofolo

\section{Abstract}

$\mathrm{T}$

here has been public outcry in South Africa about poor performance of municipalities. That many municipalities are not living up to expectations is confirmed research. Currently, the Department of Cooperative Governance and Traditional affairs (CoGTA) has developed a Local Government Turnaround Strategy (the LGTAS, 2009) in an attempt to address areas that are riddled with poor performance. A workable theoretical framework is required in municipalities to help bring about change initiatives and reinforce intended change in organisational aspects as captured in the LGTAS (2009). A model for achieving effective organisational change is proposed as the basis for municipal administrative functions and reinforcement of the turnaround strategy.

Keywords: Turnaround Strategy, Municipality, Improved Performance, South Africa

VOLUME 1 (2) 2012

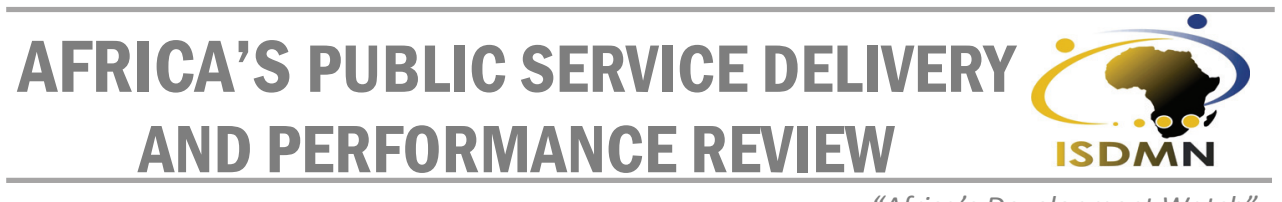

"Africa's Development Watch" 


\section{INTRODUCTION}

The literature indicates that performance of many South African municipalities is below expectation (Government Digest, 2004:13-14; Hinsch, 2009:41-43; \& Naidoo, 2010:81). The State of Local Government in South Africa overview report (2009:3) also confirms this phenomenon, stressing critical areas of the local government system mirror signs of difficulty or distress. To this effect, the Department of Cooperative Governance and Traditional affairs (CoGTA) has developed the Local Government Turnaround Strategy (2009) (hereafter, the LGTAS) in an attempt to address aspects of municipalities riddled with poor performance.

It can be argued that turning around municipalities calls for a degree of knowledge and innovation, in particular from senior officials, around the implementation of appropriate theoretical perspective. Thus, the premise of this article is that senior municipal officials need to be empowered in order to follow a theoretical framework which should be suitable to bring about change and strengthen organisational aspects as captured in the LGTAS (2009). The paper first contextualises and conceptualises organisational change as a variable that can provide the context within which the change model can be properly put to use. Secondly, specific change objectives for municipalities suggested by the LGTAS (2009) for municipalities are explored. Finally, a suggested theoretical model for achieving effective organisational change, as the basis for required municipal administrative functions and a supplement to the turnaround strategy, is proposed.

\section{ORGANISATIONAL CHANGE AS A VARIABLE}

According to McLagan (2002:28) organisational change is a somewhat recent management topic across the world today. As a result, King and Anderson (2002:4) reveal that organisational change "generally indicates a macro-level approach, which is more concerned with the organisation as a whole and its major subsystems than with the experiences of small work groups and individuals". Thus change in an organisation, such as a municipality should be on a large scale. In other words, such change should focus directly on the municipal organisational level and its sub-components.

One of the fundamental requirements of change is for senior officials in municipalities to realise that change is costly, arduous and intellectually demanding as it affects the whole organisation. For that reason, Atkinson (2005:14) states that most organisations fail to implement change. Additionally, 
Burns (1996) cited in Paton and McCalman (2001:36) indicates that change in itself is not a problem, but that a problem lies in the ineptness of leaders to lead change. Cummings and Worley (2005:61) refer to this phenomenon as "technical ineptness dilemma", which means inability to implement change processes, systems, and practices in an organisation.

Tissari and Heikkila (2001:331) state that leadership plays an integral role for successful change process in an organisation. However research, including findings in Atkinson (2005:14) suggests there is a growing inability on the part of leaders to lead change within today's complex, dynamic and challenging environment. In view of this, it appears that an effective theoretical framework is needed to guide senior officials in municipalities to lead the change process efficiently and effectively in order to bring about required municipal administrative functions and realise the objectives of the LGTAS (2009). For this reason, it is important for leaders in municipalities to have clarity of thought when bringing about their own change initiatives and fulfilling the requirements of the LGTAS (2009). The design of organisational change should not be haphazardly done, but should be organised around a credible theoretical perspective, within which analytical aspects should be systematised.

\section{OPEN SYSTEMS THEORETICAL FRAMEWORK}

Having considered literature pertaining to public administration, this article considers the concept of the open systems as a change framework that could be efficient and effective in bringing required change in municipalities as public institutions. McLean (2006:65) suggests that when change is effected in an organisation, leaders should consider the implications of an open systems theory and open systems thinking.

The argument here is that organisations interact with their environments for survival and sustainability. For this reason, McShane and Travaglione (2003:17) perceive organisations such as municipalities as open systems because their survival depends on the external environment. It, therefore, stands to reason that if change is to be induced in municipalities, open systems theory should serve as a guiding theoretical framework to achieve effective organisational change.

In order to reconcile the open systems theoretical framework with the practice of public administration, firstly, composition of municipal environment is discussed in the next section, where Figure 1 illustrates how the organisationenvironment interaction in municipalities should be conceptualised. 


\section{COMPOSITION OFA MUNICIPAL ENVIRONMENT}

As indicated in the previous section, the open systems theory emphasises the interaction of external and internal environments of an organisation. The municipal environment consists of micro (or internal) environment as well as macro (or external), or rather general environment. Figure 1 illustrates the organisation-environment interaction in municipalities.

Figure 1: Conceptual model of organisation-environment interaction in municipalities

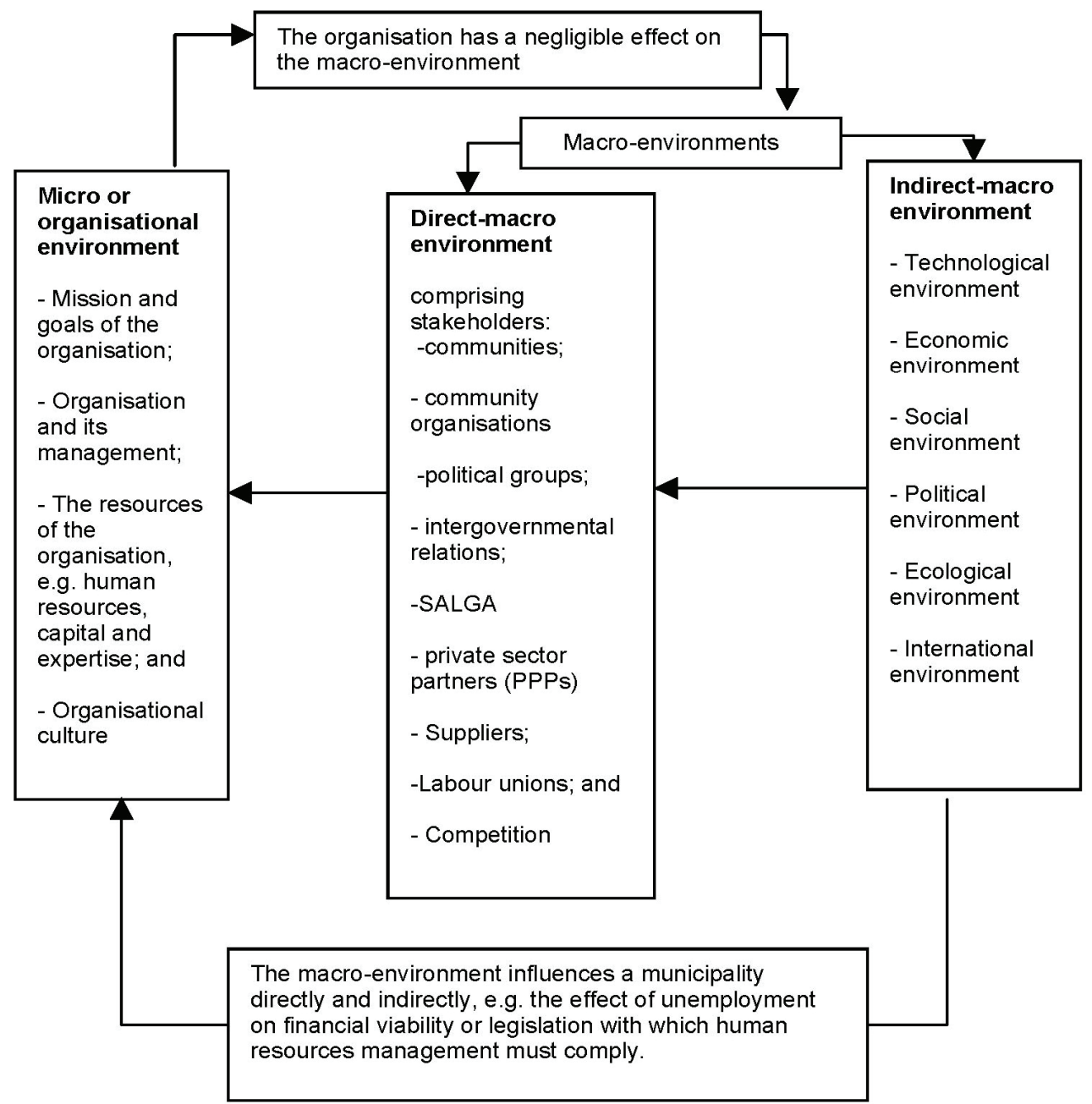

Source: Adapted from Cronje, et al., (1998) in Smit \& Cronje (2002:65) 
Figure 1 demonstrates a municipal environment that comprises factors or variables both internally and externally of organisational environments. Kreitner and Kinicki (2001:627) indicate that internal and external environmental factors or variables serve as inputs in an organisation and ultimately get transformed into outputs. Fowler (1995:31) indicates that inputs comprise needs or resources as well as means needed in a municipality. The transformation phase should consist of activities or the organisation's total activity, while output is the resultant services for promoting "good life" or general welfare. For example, needs such as unemployment and shortage of housing could be seen as influential factors for promoting general welfare of municipal inhabitants.

Resources or means contributing to inputs are raw materials, money, people (human resources), equipment, information, knowledge and legal authorisations that municipalities receive from their external environments (direct and indirect macro-environments), which should be mobilised to achieve specific outputs. The internal environment provides for the system processing (transformation), which comprises the two main components. The first, technology that refers to the tools, equipment and methods used to process inputs. Organisational behaviour and processes, the second, refers to the present patterns of interaction among individuals and groups which contribute to the transformation of inputs into outputs (Harrison \& Shirom, 1999:44-45). According to Harrison and Shirom (1999:45) the two components, inputs and processing/transformation are complemented by outputs, that is, goods and services resulting from organisational action.

Having looked at the organisation-environment interaction of municipalities, an attempt is made to raise issues captured in the LGTAS (2009), as a way of action, which CoGTA has chosen to maximise services or outputs in future.

\section{THE LOCAL GOVERNMENT TURNAROUND STRATEGY}

In short, the LGTAS (2009) was triggered by a report compiled after assessments were conducted throughout the country between April and August 2009. The assessments were as a result of a state of unrest, which was experienced in some municipalities because of lack of service delivery and poor performance in the country (State of Local Government in South Africa: overview report, 2009).

Considering the influence of micro and macro-environments on municipalities' performance, amid specific change objectives mooted by CoGTA, the LGTAS (2009:20 \& 21), identified key development areas of change for 
municipalities in South Africa. As such, these public organisations are being instructed to:

- reflect on their own performance and designed turnaround strategies to focus on establishing positive Councils with visionary and accountable leadership;

- embark on appropriate set of powers and functions and identify and establish relevant agency arrangements with national and provincial government within legal framework;

- develop professional administration that supports the political vision contained in the electoral mandate;

- concentrate on properly constituted corporate services, technical services and financial management functions, including recruitment and skills retention policies ensuring 'right people in the right job';

- provide basic services and ensuring that all money spent are well considered and accounted for in order to uphold the principle of 'value for money'; and

- through the municipal Spatial Development Frameworks, each municipality is ordered to be aware of and be able to guide the land usage on every square meter and kilometre in its area of jurisdiction.

In the same way, to improve internal or micro-environment municipalities are also instructed further to:

- optimise revenue collection and improve billing, customer care, indigent and credit control policies - 'balance the books';

- work towards sustaining "clean" audit outcomes by 2014, and those that can achieve the target earlier are requested to do so; and

- improve public participation and communication including effective complaint management and feedback systems.

Consequently, in addition to external or macro environment, the LGTAS (2009:21-22) outlines how the three spheres of government will improve intergovernmental relations, the manner in which political parties will promote institutional integrity of municipalities, and how procedures of good citizenship would be designed. 
Regarding these objectives, this article perceives open systems theory as an appropriate framework to be considered by municipalities in bringing their own change and meeting the aspirations of CoGTA.

Cummings and Worley (2005:89) suggest that content or substance of a change programme or rather analytical issues in open system organisations like municipalities include the influence of the macro-environment on organisations. Consequently, if change is to be effected, it should concentrate on the organisation as a whole, that is organisational level, and subsequently on group as well as individual levels to achieve alignment.

Figure 2 proposes a model for analytical issues which should be considered when municipalities bring change as well as reinvent themselves for effective performance.

\section{PROPOSED MODEL OF ANALYTICAL ISSUES IN MUNICIPALITIES}

As earlier noted, change should be seen, interpreted and linked both to an intraorganisational and a broader context. Figure 2 illustrates the boundaries within which the change should occur in municipalities.

Figure 2: Conceptual Model of analytical issues when bringing change in municipalities

\begin{tabular}{|c|c|c|c|}
\hline $\begin{array}{l}\frac{\text { Direct and }}{\text { indirect }} \\
\frac{\text { macro- }}{\text { environments }} \\
\text { - Inputs (see } \\
\text { figure. 1) }\end{array}$ & $\begin{array}{l}\text { Micro or } \\
\text { Organisational } \\
\text { level } \\
\text { - Strategy } \\
\text { - Technology } \\
\text { - Structural } \\
\text { system } \\
\text { - Human } \\
\text { resource } \\
\text { systems and } \\
\text { Measurement } \\
\text { systems } \\
\text { - Organisational } \\
\text { culture }\end{array}$ & $\begin{array}{l}\text { Group level } \\
\text { - Goal clarity } \\
\text { - Task structure } \\
\text { - Group } \\
\text { composition } \\
\text {-Group } \\
\text { functioning } \\
\text { - Group norms }\end{array}$ & $\begin{array}{l}\text { Individual } \\
\text { level } \\
\text {-Personal } \\
\text { characteristics } \\
\text { (age, } \\
\text { education, } \\
\text { experience, } \\
\text { skills and } \\
\text { abilities) } \\
\text { - Job } \\
\text { dimensions } \\
\text { (skill variety, } \\
\text { task identity, } \\
\text { task significant, } \\
\text { autonomy and } \\
\text { feedback) }\end{array}$ \\
\hline
\end{tabular}

Source: Adapted from Cummings and Worley, (2005:89) 
Figure 2 illustrates how boundary elements affect each other. Direct and indirect macro-environments are inputs to micro or organisational design. Organisational design becomes an input to group design, which automatically serves as an input to individual job design. The boundary elements must be aligned and fit each other if effective performance is to be achieved (Cummings \& Worley, 2005:88). Therefore, organisational interventions in municipalities should follow the procedures recommended in the next subsections.

\section{Environmental scanning}

Literature reflects that human beings do not live in isolation from their environment. Therefore, municipalities as public institutions rendering services to their constituents are susceptible to change happening in their environments. For this reason, change should have a continuous influence on the rendering of public services. Thus, chief officials should be sensitive to environmental changes. It is essential that they should understand the interdependency of municipalities and their environments.

Senior municipal officials should conduct an environmental inspection in order to carefully search for information about the external environment and problems experienced internally, which are regarded as by-products of environmental forces that might have an effect on municipal service delivery. They should be able to see opportunities and threats, as well as strengths and weaknesses that could affect service delivery in the future.

\section{Bringing about change on micro or organisational level}

This article recommends that design of interventions in municipalities at organisational level concentrate on strategy, technology, structural system, measurement systems, human resource systems and organisational culture. These components of organisational design should form inputs in municipalities to respond to the external and internal variables of the municipal environment.

Strategy: as reflected in the research literature, a challenge to senior officials is to develop strategies that should work effectively and cope with environmental forces affecting municipalities. Strategies should be able to achieve a long-term vision as well as mission and values intended to promote general welfare of inhabitants. Parker (2006:5) argues that in the context of entrepreneurship, vision should never be an end in itself, but has to be converted into realistic projects, which should also be linked to a detailed action plan. The same 
procedure is also applicable in public administration, as administration should be carried out with purpose and intent and should always deal with achievement of specific and expressed objectives.

It is fundamental that all stakeholders involved in municipalities, that is, councillors and employees have a shared vision, which must be accepted by communities or local inhabitants who should also exert themselves to the full in order to attain it. Communities should demonstrate their support to the vision by duly paying for services and holding councillors and officials accountable. Without a shared vision, municipalities would not be able to enlist the necessary support and uphold performance behaviour that should be assumed by all stakeholders to achieve service delivery.

In short, vision in municipalities should be upheld by all stakeholders and experienced through implementation of goals and objectives rather than being seen as fulfilment of policy requirements.

Technology: The usage of technology in municipalities should be regarded as a highly important issue, particularly if these public institutions are to make an impact on service delivery. In essence, some departments, particularly those with a wide range and diverse activities, will need computer facilities for data collection and processing demand as per budgetary, financial control and bookkeeping system requirements. Thus, methods and procedures in municipal departments would need to be upgraded taking into consideration changing circumstances and the appearance of new technological modus operandi.

Municipalities should have adequate technological resources, such as computers, printers, fax machines and photocopiers, and software packages that would enable employees to communicate within a required time limit, and for information to flow from one department to another. To this effect, it could be said that technological resources should be regarded as one of the means to make service delivery possible in municipalities. Therefore, from an administrative point of view, senior officials should make appropriate technological resources available for employees to be effective and efficient in doing their work.

Structural system: Organisational structures in municipalities should be organised in such a way as to divide the work into various units, which ultimately could be used to assign tasks to groups as well as to individuals. Consequently, these structures should facilitate co-ordination of work units to complete the total organisational work. For effective functional activities to be carried out in a purposeful and goal-oriented manner, it is recommended that municipalities 
have flatter, leaner, strategic based, quality-focused, flexible, and more responsive organisational structures.

Human resource systems: Human resource systems and measurement systems are matters of policy requirements in municipalities. These policy mandates should be carried out following various aspects of the employees' functions, such as the procedures for the appointment, performance measurement, training and development, and promotion of municipal officials and employees. Furthermore, senior officials should be aware that all employees in municipalities should not only be subject to decisions of councils, but also take part in decisionmaking. Use of a consultative process in order for all concerned to make input and be aware of specific requirements would prevent deviation during policy implementation. Representativity of employees at operational level could be achieved through Local Labour Forums (LLFs).

Organisational culture: Municipalities should have value systems that promote the culture of good performance. In order to achieve good performance, values should be developed to support the vision and mission of municipalities as shown previously. LLFs should be consulted when values or behavioural principles meant for employees are developed. For values to be practised, municipalities should hold workshops for employees to acquire knowledge relevant to these values.

\section{Bringing change at group or departmental level}

Senior officials in municipalities should consider the effectiveness of group design components, such as goal clarity, task structure, group composition, group functioning, and group norms at group or departmental level in order for employees to perform as expected.

Goal clarity: Organisational goals are ideals or aims, which a service organisation strives to accomplish. Achievement of goals means providing services as planned. Therefore, goals should be both challenging and realistic.

Luthans (2002:522) indicates that findings of research conducted on the importance of difficult and challenging goals reveal that goal difficulty, when combined with goal clarity, lead to increased reports of effort, which in turn, leads to more positive self-reports of performance.

This position suggests that groups or departments in municipalities should understand their goals. Resources (workers, time, money and equipments) as 
enabling requirements should be made available in order for objectives to be attained meaningfully. Senior officials should ensure that employees are aware of what is required of them. As such, performance agreements and job descriptions should include performance objectives and targets that municipal departments or groups should be striving for, and time frames within which objectives and targets should be met.

Task structure: According to Hersey, Blachard and Johnson (1996:182) task structure is the degree of routine versus challenges in the duties that the group has to perform. Robbins, Odendaal and Roodt (2001:246) perceive task structure as the extent to which work assignments are designed. In this way, in order for goals to be successfully achieved in municipal departments or groups, task structures and objectives within employees' job descriptions should be clearly expressed and well defined.

Group composition: Normally, group activities in a municipality need a variety of skills and knowledge from those concerned. This suggests that heterogeneous groups would be effective and efficient because they are likely to have diverse abilities and information regarding the activities of a municipality. This position is generally supported by research studies. It has found that when a group or department is characterised by different personalities, gender, age, education, functional specialisation and experience, there is a high expectation that the group will perform its tasks very well (Robbins et al., 2001:186).

Group functioning: Group functioning is the lifeline of the group. The manner in which members relate and engage one another in the group, is fundamental for achievement of co-operative effort.

The quality relationship of the group translates itself into good performance. Conversely, interpersonal competitions and conflicts usually result in disintegration of the group members, and average performance. Group functioning, therefore, should focus on work related activities or cyclical group inter-related processes (Cummings \& Worley, 2005:102). This perspective should be promoted in municipalities, in order for workers to stay focussed on service responsibilities, and be able to fulfil their moral obligation towards rendering efficient and quality service.

Performance norms: In order to build well-performing group in municipalities, norms and standards must be established, including rules and work processes. It should be ensured that group members abide by rules and work processes. Set standards normally result in the best quantitative and qualitative work 
performance, while norms guide the manner in which members of the group interact. For example, norms guide how decisions should be made, who should report to whom and in what way information should be communicated, as well as the manner in which disagreements should be handled (Hersey et al, 1996:550; Cummings \& Worley, 2005:102).

\section{Bringing change at Individual level}

Effective performance of operational and auxiliary staff members should be considered the basis of achieving success in municipalities. Therefore, individual job designs should strive for best performance to unlock optimal potential of employees. According to Hackman and Oldham (1976:250-279) cited in Robbins et al. (2001:33) and Newstrom and Davis (2002:247-248), any work in organisations can be designed according to five core job dimensions emphasising elements of motivation and job satisfaction, as discussed in the sections that follow.

Skill variety: This refers to the extent to which the job needs a variety of different activities in order for the workers can utilise a number of different skills and knowledge. Individual jobs in municipalities should be designed to accommodate a variety of activities in order for skills, abilities and talents of employees to be used properly.

Task identity: This means the extent to which the job requires completion of a full and identifiable piece of work. In this way, leaders should design or structure individual jobs in such a way that operational and auxiliary staff members are able to complete the whole and identifiable piece of work themselves. This means that a staff member should be assigned work that he/she would do from start to completion, with a positive outcome.

Task significance: This refers to the degree to which the job has a large impact on other people's lives. Managers should ensure that individual staff members have knowledge of their task objectives and know in what way the assigned objectives relate to other tasks in municipalities. In other words, it is crucial for staff members to know the roles they play in the total endeavour. This position would lead an individual staff member to realise the importance of his/her task and what impact the task has on the total accomplishment of organisational goal. 
Autonomy: This means the extent to which the job supplies significant freedom, independence and judgment to the individual in programming the work and in determining the procedures to be used in executing it. It is significant that managers in municipalities provide a degree of freedom, independence and discretion to staff members, which could enable them to plan and decide on procedures to follow when doing their jobs. Autonomy empowers staff members to take full responsibility for their tasks' results, and also promotes learning experience.

Feedback: This refers to the extent to which a job gives workers direct and clear information about the effectiveness of task achievement. Job design of employees in municipalities should be formulated in order to provide feedback with regard to the way task activities are done. In fact, a well-completed and well-done job would provide clear information about the efficiency of operational or auxiliary staff members.

Having explored the analytical issues or content of analysis and implementation process, this article contends that critical and fundamental aspects of organisational design in municipalities could be streamlined to supplement the attempt at improvement envisaged by the LGTAS in municipalities.

\section{CONCLUSION}

This article is premised on the idea that an effective "way of doing things" is required in municipalities to bring about change and supplement organisational aspects as captured in the LGTAS (2009). To this effect, it has been highlighted that one of the fundamental requirements of change is for leaders or managers in municipalities to realise that change is demanding as it affects the whole organisation.

In order to achieve effective organisational change, this article has argued that it is essential for senior officials in municipalities to be theoretically grounded when bringing about change initiatives and fulfilling the requirements of the LGTAS (2009) as design of organisational change should be properly organised around a credible theoretical perspective, which subsequently should inform and guide execution of the plan.

This article regards open systems theory as a suitable theoretical framework that could be used in order to inform and guide effective achievement of organisational change in municipalities. In addition, the article suggests this theoretical framework could benefit municipalities in future as they attempt to 
reinvent themselves to achieve effective service delivery. Furthermore, the proposed theoretical model could promote the concept of organisational learning since a broader view of municipal environment and factors that influence functional activities would have to be considered in order to guide all strategic decisions.

\section{List of References}

- ATKINSON, P. 2005. Managing resistance to change. Management services. 46(1): 14-19, Spring.

- CUMMINGS, T.G. \& WORLEY, C.G. 2005. Organisation development and change. Thomson: South-Western.

- FOWLER, A. 1995. Human resource management in local government: Its special purposes, conditions and tasks. London: Pitman.

- GOVERNMENT DIGEST. 2004. Research reveals reasons for non-delivery by municipalities. Government digest, 1(24): 13-14, Aug.

- HARRISON, I.M \& SHIROM, A. 1999. Organisational diagnosis and assessment: Bridging theory and practice. London: Sage.

- HERSEY, P., BLANCHARD, K.H. \& JOHNSON, D.E. 1996. Management of organisational behaviour: Utilising human resources. New Jersey: Prentice Hall International.

- HINSCH, M. 2009. Current service delivery challenges for municipalities with regard to water management. Civil Engineering, 17(5): 41-43, June.

- KING, N. \& ANDERSON, N. 2002. Managing innovation and change: A critical guide for organisations. Australia: Thomson.

- KREITNER, R. \& KINICKI, A. 2001. Organisational behaviour. 5th ed. New York: Irwin Mcraw-Hill.

- LUTHANS, F. 2002. Organisational behaviour. 9th ed. Boston: Irwin McGraw-hill.

- McCLAGAN, P. 2002. Change leadership today: Why we need to rethink change. In R. Havenga (Ed.). Management Today, 18(7): 28-31. 
- MCLEAN, G.N. 2006. Organisation development: Principles, processes and performance. San Francisco: Berrett-Koehler Publishers, Inc.

- MCSHANE, S. \& TRAVAGLION, T. 2003. Organisational behaviour on the specific rim. North Ryde: McGraw-Hill.

- NAIDOO, R. 2010. Bigen Africa asks: Are Government's "Breaking New Ground" mixed-mode settlements addressing the housing backlog? Civil Engineering, 18(3):81, April.

- NEWSTROM, J.W. \& DAVIS, K. 1997. Organisational behaviour: Human behaviour at work. Boston: McGraw-Hill.

- PARKER, E. 2006. Eric Parker's road map to business success. 1st ed. Northcliff: Frontrunner (Pty) Limited.[ 31 ]

- PATON, R.A. \& McCALMAN, J. 2001. Change management: A guide to effective implementation. London: SAGE.

- ROBBINS, S.P., ODENDAAL, A. \& ROODT, G. 2001. Organisational behaviour: Global and Southern African perspective. Cape Town: Pearson education South Africa.

- SMIT, P.J. \& CRONJE, G.J. 2002. Management Principles: Contemporary edition for Africa. 3rd ed. Cape Town: Juta \& Co, Ltd.

- SOUTH AFRICA. 2009. Local Government Turnaround Strategy: Working together, turning the tide in Local Government. Pretoria: Government Printers.

- SOUTH AFRICA. 2009. State of local government in South Africa: overview report. Pretoria: Government Printer.

- TISSARI, T. \& HEIKKILA, J. 2001. Successful re-engineering: learning by doing. International journal of logistics: Research and Applications, 4(3): 329-344, Nov.

\section{AUTHOR'S CONTACT:}

\section{Malefetsane Mofolo}

Faculty of Management Sciences

Governance \& Public Management

Walter Sisulu University of Technology

Email: mmofolo@wsu.ac.za 